\title{
Editorial change
}

Dr Michael J. Rycroft, the Editor responsible for Atmospheric Sciences, resigned on 31 December 1990. Dr Rycroft left British Antarctic Survey and took up a new post as Professor and Dean of the School of Aeronautical Studies, Cranfield Institute of Technology, during 1990. He played a key role in the establishment of Antarctic Science and took every opportunity to stimulate submissions from atmospheric scientists whose work he believed was of interest and value to a multi-disciplinary audience.

The new editor is Dr Stephen D. Mobbs, Department of Applied Mathematics, University of Leeds. Dr Mobbs has a first degree in physics and a PhD in applied mathematics. His research interests are in meteorology and climatology, with particular reference to stably stratified flow, internal gravity waves and boundary layer meteorology. Dr Mobbs is currently working with British Antarctic Survey on a study of blowing snow at Halley. 